Indexed by

\section{Scopus}

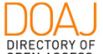

DIRECTORY OF
OEN ACESSS
JOURNALS

Crossref
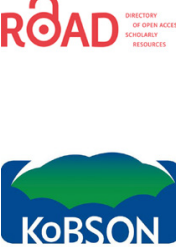

811 Google

\title{
DEVELOPMENT OF AN APPROACH TO DETERMINATION OF COUPLING QUALITIES OF ROAD COVERING USING WEATHER-CLIMATE FACTOR
}

\section{Anastasia Shevtsova}

Belgorod State Technological

University named after V.G.

Shukhova, Transport and

Technological Institute,

Department of Operation and

Organization of Vehicle Traffic,

Belgorod, Russia

\author{
Alexander Novikov \\ Oryol State University named \\ after I.S. Turgenev, Polytechnic \\ Institute named after N.N. \\ Polikarpova, Department of \\ service and repair of machines, \\ Orel, Russia
}

Key words: coefficient of friction, test methods, mathematical analysis, dependence, weather and climate conditions. residues, information and logical model of the process, modeling of technological process

Cite article:

Anastasia, S., \& Alexander, N. [2021]. Development of an approach to determination of coupling qualities of road covering using weather-climate factor. Journal of Applied Engineering Science, 19(1) 30 - 36. DOI:10.5937/jaes0-26642

Online aceess of full paper is available at: www.engineeringscience.rs/browse-issues 


\title{
DEVELOPMENT OF AN APPROACH TO DETERMINATION OF COUPLING QUALITIES OF ROAD COVERING USING WEATHER-CLIMATE FACTOR
}

\author{
Anastasia Shevtsova ${ }^{1 *}$, Alexander Novikov ${ }^{2}$ \\ ${ }^{1}$ Belgorod State Technological University named after V.G. Shukhova, Transport and Technological \\ Institute, Department of Operation and Organization of Vehicle Traffic, Belgorod, Russia \\ ${ }^{2}$ Oryol State University named after I.S. Turgenev, Polytechnic Institute named after N.N. Polikarpova, \\ Department of service and repair of machines, Orel, Russia
}

Assessing the grip of the road surface is an extremely important task both in the field of traffic management, and in the field of investigation and examination of traffic accidents. The coupling quality of the road surface is fully ensured by the coefficient of friction, which is subject to constant monitoring in order to ensure road safety. There are a large number of methods for determining the magnitude of the coefficient of friction. In their study, the authors propose an improved approach for determining the investigated value using the weather and climate factor. Previously, a group of researchers in the course of scientific research determined the dependence of the coefficient of friction on the temperature of the road surface, as a result of mathematical analysis, the authors obtained a dependence that allows to determine the studied value by air temperature and the condition of the road surface (presence of precipitation). The performed experiment allowed us to test the obtained dependence within the framework of the object of study and to make a comparative assessment of the results obtained with the data obtained using the road laboratory.

Key words: coefficient of friction, test methods, mathematical analysis, dependence, weather and climate conditions. residues, information and logical model of the process, modeling of technological process

\section{INTRODUCTION}

Most traffic accidents occur due to unsatisfactory road conditions and the inability of existing approaches to traffic management to change these conditions. Using road stations to analyze changes in road conditions, namely weather and climatic factors, is a rather expensive undertaking, which for small and medium-sized cities is an unrealizable undertaking. In this regard, the study of changes in the weather and climate factor on the example of one of the regions of the Russian Federation and the assessment of its influence on the change in the adhesion qualities of the road surface will reduce the risk of traffic accidents.

One of the main parameters determined during the examination of a traffic accident is the coefficient of friction $(\varphi)$ of tires of a car with a road surface, this parameter is one of the main factors characterizing road safety. The coefficient of adhesion of tires to the road has a significant impact on the braking parameters of the car, its stability, acceleration dynamics, as well as cross-country ability. A decrease in the coefficient of adhesion leads to an increase in the path and time of braking, a decrease in the stability of the car, a decrease in the acceleration dynamics of the car due to slippage of the drive wheels, and also significantly worsens the passability of the car [1].

Coefficient of friction is the ratio of the maximum possible value of the adhesion between the tires of the vehicle and the road surface to the weight of this vehicle in a given section of the road:
$\varphi=\frac{F_{t r}}{G_{v}}$

where $\varphi$ - coefficient of friction; Ftr - traction force between the tires of the vehicle, $\mathrm{kN} ; \mathrm{Gv}$ - vehicle weight, kN.

The need for determining the coefficient of friction arises when calculating the steady-state deceleration during emergency braking of the vehicle, as well as solving a number of issues related to maneuvering the vehicle and driving on sections of roads with large slopes [2]. A number of factors, among which we can distinguish, significantly affects the coefficient of friction: the composition of the rubber and the condition of the tire treads vehicle speed, type and quality of road surface, as well as a number of other factors that are difficult to take into account [3].

Earlier, the team of authors in the performed studies found that the value of the coefficient of friction affects the mode of movement of the traffic flow in terms of controlling it with the help of a traffic light object $[4,5]$. This parameter affects the value of the throughput value depending on changes in weather and climate conditions and its consideration both during the examination of a traffic accident and when establishing a traffic flow control regime is an extremely important task. In this regard, the main purpose of this study is to develop a method for determining the coefficient of friction based on the use of the weather and climate factor.

In order to analyze the main approaches to determining the investigated value, the authors performed an analysis of existing scientific methods. 


\section{METHODOLOGY}

\section{Analysis of existing methods for determining the coefficient of friction}

As a result of the analysis of the scientific literature [614], three main methods were determined for determining the parameter under study - the coefficient of friction, depending on the basic conditions for determining this quantity, the authors proposed a classification of existing methods (Fig. 1).

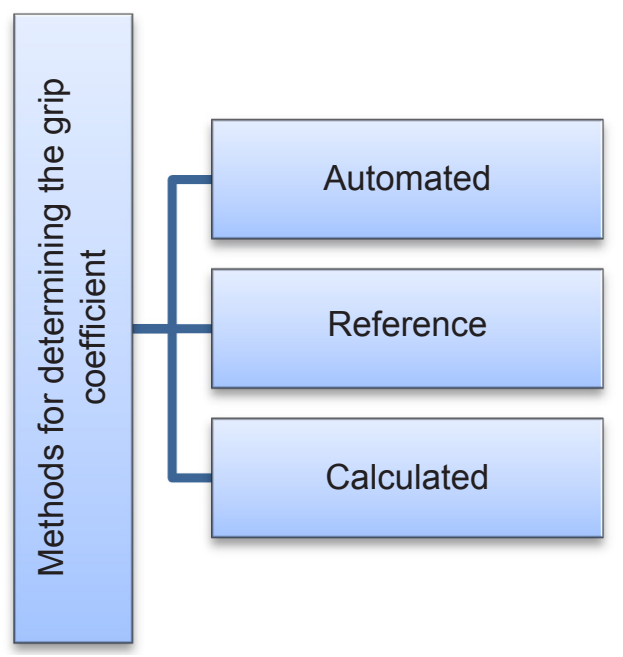

Figure 1: Classification of methods for determining the coefficient of friction

1. Automated method is based on the use of specialized equipment that allows in real conditions on a certain section of the road network to make a measurement of the studied value. Under this method, such equipment is understood as specialized equipment $[6,7]$ (Fig. 2) and specialized laboratories (Fig.3) [6, 8, 9]. Determination of the investigated value using an automated method (special devices and laboratories) is the most accurate, but at the same time, the most time-consuming method is to measure the coefficient of friction using special equipment. This method allows you to determine the actual coefficient of friction on a section of the road network, but testing this method requires significant time and labor costs.

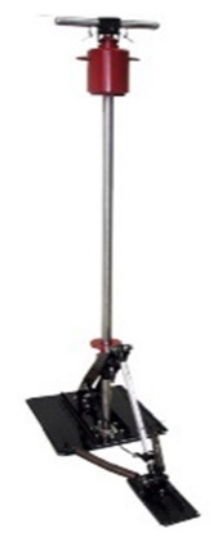

Figure 2: General view of the coupling coefficient of friction meter portable CGCp-2M

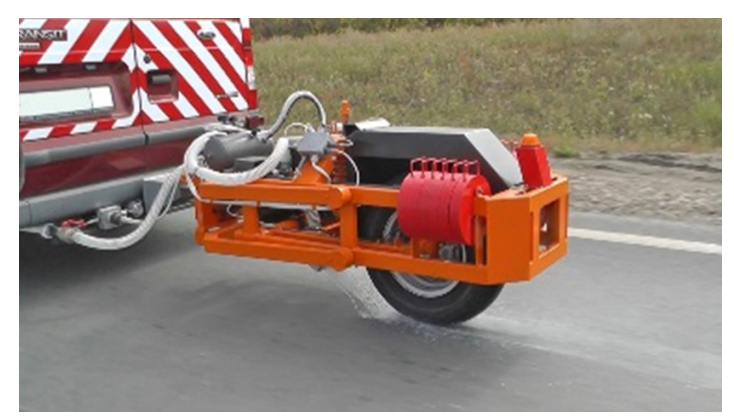

Figure 3: Car installation type EGMD-2 (Evenness and Grip Monitoring Device)

2. Reference method, based on the determination of the coefficient of friction using normative sources that allow the type of coating and its condition to determine the value of the coefficient. Specialists do not always have the practical ability to measure the actual coefficient of friction on the test site. To simplify calculations, tabular values of coupling coefficients from various reference books are often used $[10,11]$. The reference lists the range of coupling coefficients for typical road surfaces under various road conditions (dry, wet, dirty, snow-covered, icy). These coefficient values are obtained on the basis of numerous empirical measurements using special equipment in accordance with normative sources. It is important to know that tabular values of the coupling coefficient can only be used for estimation calculations. For an objective assessment of the condition of the road surface, it is necessary to make full-scale surveys on the ground.

3. Calculated method, based on establishing the dependence of the coefficient of temperature of the road surface. Petrov M. A. when analyzing experimental data obtained at different times by many researchers, the following pattern was revealed: on road surfaces covered with snow and ice, the coefficient of friction increases with a decrease in temperature. Moreover, particularly significant changes are observed in the temperature range from $0^{\circ} \mathrm{C}$ to $-15^{\circ} \mathrm{C}$ [12]. This pattern was confirmed in the works of Evtyukov S. A. [13] and Botvinev N. Yu [14]. In these works, the dependence of the coefficient of friction on the temperature of the road surface in the temperature range from $-20^{\circ} \mathrm{C}$ to $+20^{\circ} \mathrm{C}$. A graphical representation of the dependency is shown in figure 4 .

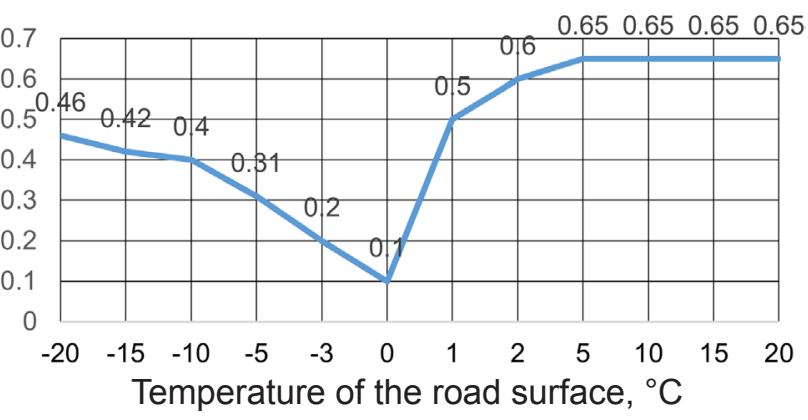

Figure 4: Dependence of the coefficient of friction of adhesion on the road surface temperature [13]

Istraživanja i projektovanja za privredu ISSN 1451-4117 Journal of Applied Engineering Science Vol. 19, No. 1, 2021 
As can be seen from the graph (Fig. 4), in the temperature range of $+5^{\circ} \mathrm{C}$ to $+20^{\circ} \mathrm{C}$ coefficient of friction almost does not change and is in the range of $0.6-0.7$. When the temperature drops below $+5^{\circ} \mathrm{C}$, there is a sharp decrease in the coefficient of friction. At a temperature of $0^{\circ} \mathrm{C}$, the coefficient of friction reaches its lowest value of 0.1 . With a further decrease in temperature, the coefficient of friction increases. In the range from $0^{\circ} \mathrm{C}$ to $-15^{\circ} \mathrm{C}$ there is a sharp increase in the coefficient up to 0.4 , after which the coefficient changes slightly.

The method of determining the coefficient of friction using the above dependence can be used to quickly obtain information about the current value of the coefficient of friction for a particular section of the road. The advantage of this method compared to automated and reference (Fig. 1) is its simplicity and speed of data acquisition, which is especially important when constructing adaptive traffic control algorithms.

The third method is one of the most promising in determining the investigated parameter because in this method it is possible to use a mathematical approach to estimating the parameter by the weather and climate factor. To develop an approach to determining the coefficient of friction using the considered factor (weather and climate), the authors performed studies using the mathematical apparatus to obtain the necessary approach.

\section{Development of an approach to determining the coefficient of friction using the weather-climate factor}

The difficulty of using the third method, the calculation method, is to determine the temperature of the road surface, which implies the presence of automatic road weather stations (ARWS). This equipment is quite expensive and its use in urban conditions is unprofitable. One of the alternative methods for determining the temperature of the pavement is to establish its relationship and dependence with the temperature of the pavement. As is known, the temperature of the asphalt concrete pavement is a function of air temperature, and it substantially depends on solar radiation, the course of temperatures in the soil of the subgrade, as well as on many other factors $[15,16]$.

Field observations of the temperature at stationary meteorological stations have unequivocally shown that in winter, asphalt concrete pavement maintains a higher temperature than the minimum ambient temperature [17]. So, for example, in the 2 road-climatic zone at an average daily air temperature of $-28.8^{\circ} \mathrm{C}$, the temperature of the asphalt concrete coating near the surface (at a depth of $1.5 \mathrm{~cm}$ ) was $-16^{\circ} \mathrm{C}$ according to the measurements [18]. This means that the minimum temperature of the asphalt concrete coating turned out to be almost $13^{\circ} \mathrm{C}$ higher than the minimum temperature of the outside air. It is obvious that the sharper the air temperature decreases, the higher the difference between the coating and air temperatures due to the thermal inertia of the road structure.

At different times, a large number of researchers have studied the relationship between air and pavement temperatures $[19,20]$. The analysis of experimental data shows that the most accurately calculated surface temperature of the asphalt concrete pavement could be determined depending on the ambient temperature in the form of a broken line drawn through 3 points that correspond to the maximum, minimum and average annual air temperatures.

Therefore, to plot the dependence of the temperature of the asphalt concrete pavement on the ambient temperature, it is necessary to determine the maximum, minimum, and average annual air temperatures for the study area, as well as calculate the temperature of the asphalt pavement at these points.

It is worth noting that the values of the average annual, minimum and maximum air temperatures for all subjects of the Russian Federation, which is represented by 5 climatic zones, are given in a specialized code of rules [21].

The methods for calculating the maximum and minimum temperatures of asphalt concrete pavements are given in the works of many researchers [17, 22-24]. Kovalev Ya. N. in his research work [23] proposes to determine the minimum temperature of an asphalt concrete pavement using the following formula:

$T_{s}^{\min }=0.7 \cdot T_{\text {air }}^{\text {min }}$

where $T_{s}^{\min }$ - estimated minimum surface temperature of the asphalt concrete pavement, ${ }^{\circ} \mathrm{C} ; T_{\text {air }}^{\text {min }}$ - the minimum temperature of the outside air, ${ }^{\circ} \mathrm{C}$.

In the summer period, the dependence of the temperature of the asphalt concrete coating on the temperature of the surrounding air will be different, primarily due to the significantly greater influence of the additional heating of the asphalt concrete by the sun's rays. Fluctuations in the temperature of the coating during the day are also sharper in the summer than winter.

The dependence of the coating temperature on the ambient temperature is justified theoretically based on the heat balance equation. To determine the maximum temperature of the pavement Ya.N. Kovalev [22] and L.I. Goretsky [23] suggest applying the following formula:

$T_{s}=T_{\text {air }}+T_{\text {eq }}$

where $T_{s}$ - temperature surface (coating), ${ }^{\circ} \mathrm{C} ; T_{\text {air }}$ - temperature air, ${ }^{\circ} \mathrm{C} ; T_{\text {eq }}$ - equivalent temperature, ${ }^{\circ} \mathrm{C}$.

The equivalent temperature is a kind of increase due to the additional heating of the coating by the sun's rays:

$T_{e q}=(1-A) \cdot j / a_{t}$

where $A$ - is the albedo of the coating surface, characterizing its reflectivity (diffuse reflection coefficient of the coating); $j$ - is the intensity of solar radiation, $\mathrm{W} / \mathrm{m}^{2}$; $a_{t}$ - is the heat transfer coefficient, determined by the ratio of the density of the heat flux given off by the surface to the temperature difference between the surface and 
the surrounding medium.

The parameters of formula (4) can change over time in a wide range depending on the actual weather-climate, landscape, thermal, structural and other factors, but these changes in the calculations can be ignored [17].

In the USA, methods for improving operational performance and service life of the road and improving road safety have been actively developed. The new method is called "Superpave" (Superior Performance Pavements) and replaced the already obsolete methods "Hveem" and "Marshall". The main points of this method [24] were formulated as part of the strategic road research program (SHRP) with the involvement of the Asphalt Institute and other leading USA universities. Because of processing the measurement data, a relationship was confirmed that relates the minimum surface temperature of the asphalt concrete pavement and the minimum ambient temperature:

$T_{s}^{\min }=0.859 T_{\min }+1.7$

where $T_{\min }$ - is the minimum air temperature in the average year, established on the basis of meteorological data, ${ }^{\circ} \mathrm{C}$.

Currently, this correlation dependence (5) is the most justified experimentally, therefore it is precisely it that is recommended for calculating the minimum temperature of asphalt concrete pavements in any regions.

Based on the heat balance and assuming constant values in the calculations for solar absorption (0.90), radiation through the air $(0.81)$, atmospheric radiation $(0.70)$ and wind speed $(4.5 \mathrm{~m} / \mathrm{s})$, it was obtained The following equation to determine the maximum estimated coating temperature:

$T_{2}^{\max }=0.9545 \cdot\left(T_{\text {air }}-0.00618 \cdot L^{2}+0.2289 \cdot L+42.2\right)-17.18$

where $T_{2}^{\max }$ - the maximum calculated surface temperature at a depth of $2 \mathrm{~cm},{ }^{\circ} \mathrm{C} ; T_{\text {air }}$ - the seven-day average maximum air temperature, ${ }^{\circ} \mathrm{C} ; L-$ the geographical latitude of the object in degrees.

Based on numerous studies in this direction, it was concluded that the minimum temperature in the average year is approximately equal to the temperature of the coldest five-day security of 0.98 . Therefore, depending on (5), when determining the minimum design temperature of an asphalt concrete pavement, one can focus on the minimum air temperature of the coldest five-day security of 0.98 . In this case, the formula takes the following form:

$T_{s}^{\min }=0.859 \cdot T_{5 \min }^{\text {air }}+1.7$

where $T_{5 \min }^{\text {air }}$-temperature of the coldest five-day period, ${ }^{\circ} \mathrm{C}$. Kiryukhin G.N. in his article [25] performed an approximation of the experimental data obtained on the territory of the Russian Federation, in this case, the formula for calculating the maximum coating temperature takes the following form:

$T_{s}^{\text {max }}=-0.0306 \cdot T_{\text {max }}^{2}+3.8071 \cdot T_{\text {max }}-39$ where $T_{s}^{\max }$ - is the maximum temperature of the asphalt pavement, ${ }^{\circ} \mathrm{C} ; T_{\max }-$ is the absolute maximum of air temperature recorded in the considered region, ${ }^{\circ} \mathrm{C}$.

Thus, the dependence (7) determined by the "Superpave" method and adapted to Russian conditions is most applicable for calculating the minimum temperature of asphalt concrete pavement. The coating temperature when the air temperature passes through $0^{\circ} \mathrm{C}$ is assumed to be equal to the average annual air temperature. To determine the maximum coating temperature, you can use the dependency (8).

Based on the results of the obtained data and dependencies, the authors performed an experiment to determine the studied value (coefficient of adhesion) using the ambient temperature and the presence of precipitation (weather-climate factor).

\section{EXPERIMENT}

The object of the study is the Belgorod region of the Russian Federation, according to a normative source [22], the minimum air temperature of the coldest five-day period is 0.98 in the Belgorod region, the maximum temperature is $38^{\circ} \mathrm{C}$, and the average annual temperature is $6.4^{\circ} \mathrm{C}$. After determining the necessary temperature values and substituting them in the corresponding formulas (7) and (8), we calculate the maximum $T_{s}^{\max }$ and minimum $T_{s}^{\text {min }}$ temperatures of asphalt concrete pavement:

$T_{s}^{\text {min }}=0.859 \cdot(-27)+1.7=-21.5^{\circ} \mathrm{C}$

$T_{s}^{\max }=-0.0306 \cdot 38^{2}+3.8071 \cdot 38-39=61.5^{\circ} \mathrm{C}$

Using the obtained temperature values, a polyline is obtained for the dependence of the asphalt concrete surface temperature on the ambient air temperature (Fig. 5).

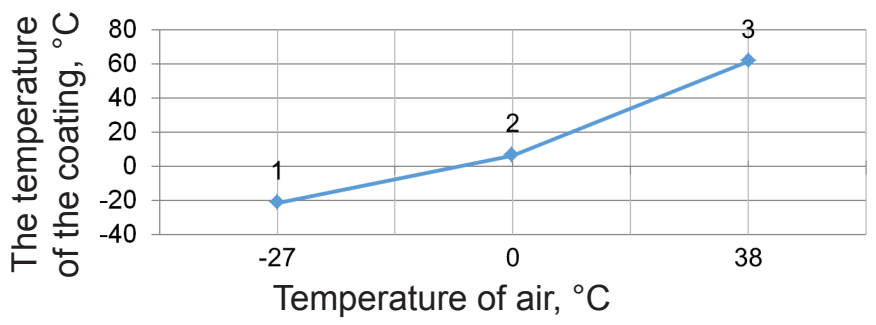

Figure 5: Dependence of the calculated surface temperature of asphalt concrete pavement on the ambient air temperature for the Belgorod region

(where 1 - minimum coating temperature; 2-average coating temperature; 3-maximum coating temperature)

We define the equation of the lines that are part of the resulting polyline, shown in figure 5 .

To plot a polyline with $T_{\text {air }} \leq 0^{\circ} \mathrm{C}$ as a specified use point $2\left(0, T_{s}^{\text {average annual }}\right)$ and point $1\left(T_{\text {air }}^{\text {min }}, T_{s}^{\text {min }}\right)$, for the area $T_{\text {air }}>0^{\circ} \mathrm{C}-2$ point $\left(0, T_{s}^{\text {average annual }}\right)$ and point $3\left(T_{\text {air }}^{\text {max }}, T_{s}^{\text {max }}\right)$. Thus, the equations of straight lines take the following general form: 


$$
\begin{gathered}
T_{\text {air }} \leq 0: \frac{T_{\text {air }}-0}{T_{\text {air }}^{\text {min }}-0}=\frac{T_{s}-T_{s}^{\text {average annual }}}{T_{s}^{\text {min }}-T_{s}^{\text {average annual }}} \\
T_{\text {air }}>0: \frac{T_{\text {air }}-0}{T_{\text {air }}^{\text {max }}-0}=\frac{T_{s}-T_{s}^{\text {average annual }}}{T_{s}^{\text {max }}-T_{s}^{\text {average annual }}}
\end{gathered}
$$

By converting the obtained equations and substituting in them the values of the corresponding temperatures for the object of research, a dependence describing the relationship between the temperature of the asphalt concrete pavement and the ambient air temperature in the territory of the Belgorod region is obtained:

$$
\begin{aligned}
& T_{\text {air }} \leq 0: T_{s}=1.033 \cdot T_{\text {air }}+6.4 \\
& T_{\text {air }}>0: T_{s}=1.45 \cdot T_{\text {air }}+6.4
\end{aligned}
$$

\section{ANALYSIS}

As a result of the analysis of the dependence of the coefficient of adhesion on air temperature, presented in Fig. 4 it was found that it is possible to distinguish 8 temperature ranges for which there is a change in the coefficient of friction (table 1).
To clarify the relevance of the obtained dependence for the Belgorod region, full-scale measurements of the coefficient of friction were carried out using the automatic method, namely, the specialized laboratory EGMD-2 (Fig. 3).

This installation consists of a car, a trailed one-wheeled device equipped with evenness and adhesion sensors, as well as wetting systems, control and registration systems installed in the car. The main technical parameters of the trailed device and a brief description of the installation are presented in table 2.

As a result of measurements, the relevance of the dependence was confirmed for dry asphalt concrete pavement. However, when measuring the coefficient of friction on a wet coating, results were obtained that significantly differed from the dependence presented in fig. 4 and tab. 1. This means that when it rains, it is necessary to adjust the ratio of the coefficient of adhesion to the ambient temperature. In fig. 6 shows the dependence of the coefficient of friction on the ambient temperature obtained using the calculation algorithm for the Belgorod region

Table 1: The value of the coefficient of friction of the road surface depending on the air temperature

\begin{tabular}{|l|c|c|c|c|c|c|c|c|}
\hline Temperature range, ${ }^{\circ} \mathrm{C}$ & $<-10$ & $-9 \ldots-5$ & $-4 \ldots-3$ & $\begin{array}{c}-2 \ldots 0 \\
\text { (inclusive) }\end{array}$ & $\begin{array}{c}0 \ldots 1 \\
\text { (inclusive) }\end{array}$ & $1 \ldots 2$ & $3 \ldots 5$ & $>5$ \\
\hline Value coefficient of friction $(\varphi)$ & 0.4 & 0.3 & 0.2 & 0.1 & 0.3 & 0.5 & 0.6 & $0.65-0.7$ \\
\hline
\end{tabular}

Table 2: Main technical parameters of the automotive installation type EGMD-2

\begin{tabular}{|l|c|}
\hline Tire sizes, inches & $6.00-13 ; 6.15-13 ; 6.40-13$ and $6.45-13$ \\
\hline Tread type & with a pattern with a depth of at least $1.0 \mathrm{~mm}$ \\
\hline Tire pressure, $\mathrm{kPa}$ & $170 \pm 20(1,7 \pm 0,2 \mathrm{kgf} / \mathrm{cm})$ \\
\hline Wheel load, $\mathrm{kN}$ & $3 \pm 0,03(300 \pm 3 \mathrm{kgf})$ \\
\hline Maximum radial runout of the rim and tire of the wheel, $\mathrm{mm}$ & $2 \pm 0,2$ \\
\hline Maximum statistical imbalance, $\mathrm{g} / \mathrm{cm}$ wheel & $50 \pm 5$ \\
\hline Coating humidification rate, $\mathrm{l} / \mathrm{m}^{2}$ & $1 \pm 0,2$ \\
\hline Speed, $\mathrm{km} / \mathrm{h}$ & 60 \\
\hline The total measurement error, $\%$ & \pm 4 \\
\hline The limits of measurement of the coefficient of friction & $0,1-1,0$ \\
\hline
\end{tabular}

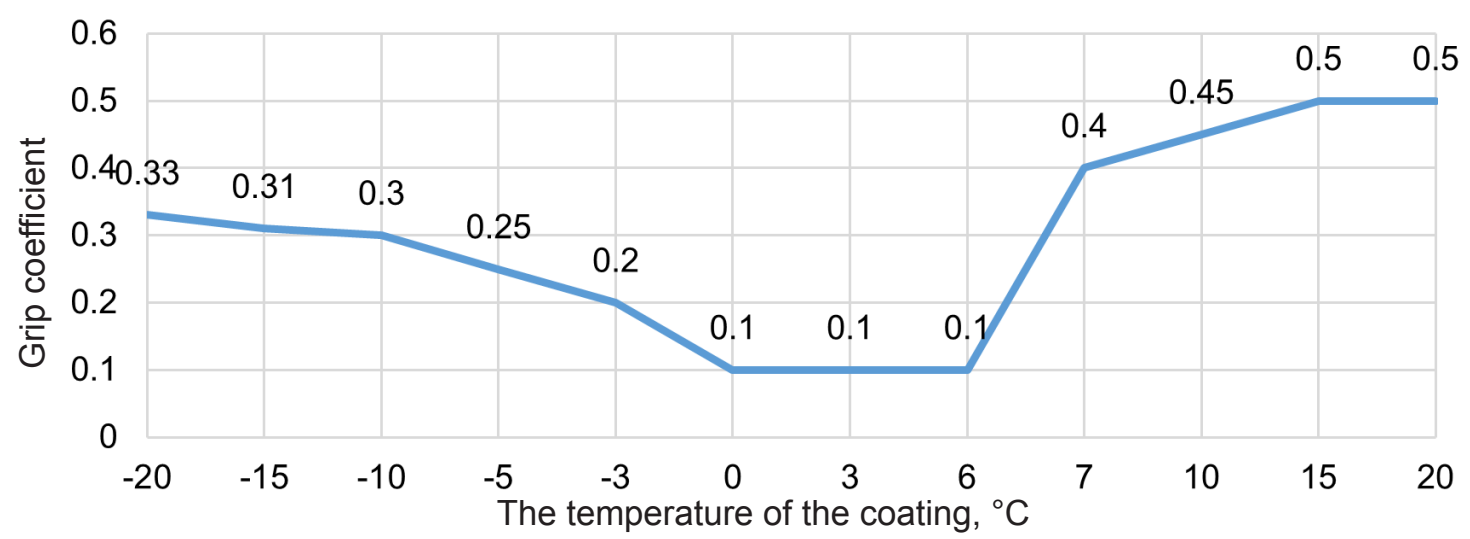

Figure 6: The dependence of the coefficient of friction on the temperature of wet asphalt pavement for the Belgorod region 
on wet surfaces after precipitation.

In fig. 6 , it is also possible to distinguish several temperature ranges at which the cohesion coefficient of friction (Table 3).

Table 3: The value of the coefficient of friction of the pavement depending on the temperature of the air and precipitation (wet surface (rain, snow))

\begin{tabular}{|l|c|c|c|c|c|c|}
\hline $\begin{array}{l}\text { Temperature } \\
\text { range },{ }^{\circ} \mathrm{C}\end{array}$ & $-20 . .-10$ & $-9 \ldots-2$ & $-2 \ldots 6$ & $6 \ldots 7$ & $7 \ldots 10$ & $>11$ \\
\hline $\begin{array}{l}\text { Value coefficient } \\
\text { of friction }(\varphi)\end{array}$ & 0.3 & 0.2 & 0.1 & 0.3 & 0.4 & 0.5 \\
\hline
\end{tabular}

As a result of the experiment, it was found that for the entire temperature range of operation of the asphalt concrete coating, a change in the coefficient of friction from 0.1 to 0.7 is characteristic.

\section{DISCUSSION}

During the study, the authors found that the coefficient of friction depends on the temperature of the pavement, which is confirmed by a number of scientific research projects, the difficulty of using this dependence is the difficulty of determining the temperature of the pavement in real conditions, which requires specialized expensive equipment. As a result of the analysis of scientific literature, it was found that the temperature of the road surface depends on the ambient temperature and the presence of precipitation, the authors refer to these characteristics as weather-climatic factors. The study of the existing dependence - the temperature of the pavement and the weather-climate factor - allowed the authors to develop a universal approach that allows, depending on the minimum set of variables, such as the temperature ranges of a particular site, depending on the climatic zone characteristic of the regions of the Russian Federation, to determine the temperature of the pavement the obtained patterns (9) and (10) and, accordingly, the value of the parameter under study - the coefficient of friction. In the future, the obtained dependencies will be used by the authors when arranging a work plan for road adaptive equipment - traffic light regulation, variable information display, controlled road signs [26-27].

\section{CONCLUSIONS}

As a result of the study, the authors obtained the following results:

1. The classification of existing methods for determining the investigated value - the coefficient of friction;

2. The dependence of the coefficient of friction and the temperature of the road surface has been established;

3. The relationship between the temperature of the pavement and weather-climate factors is determined;
4. A mathematical method has been developed to determine the temperature of the coating, depending on the value of the ambient temperature;

5. Experimental studies were carried out and the mathematical method for determining the studied value was tested and the data obtained were compared and the data obtained using the automatic method are excellent among themselves in the range $+-2 \%$ .. $5 \%$, which confirms the feasibility of the approach proposed to develop.

In the future, a promising direction is to improve the proposed approach for use in other regions of the Russian Federation, taking into account their climatic affiliation.

\section{REFERENCES}

1. Gelinne, D. (2017) Foundations of Road Safety. Carter, D. (Eds.), Road Safety Fundamentals: Concepts, Strategies, and Practices that Reduce Fatalities and Injuries on the Road. U.S. Department of Transportation. Federal Highway Administration, p. 188.

2. Evtiukov, S., Kurakina, E., Lukinskiy V., Ushakov, A. (2017). Methods of Accident Reconstruction and Investigation Given the Parameters of Vehicle Condition and Road Environment. Transportation Research Procedia, vol. 20, 185-192, DOI: 10.1016/j. trpro.2017.01.049

3. Ni, D. (2015) Traffic Flow Theory: Characteristics, Experimental Methods, and Numerical Techniques. Butterworth-Heinemann.

4. Novikov, A., Novikov, I., Shevtsova, A. (2018) Study of the impact of type and condition of the road surface on parameters of signalized intersection. Transportation Research Procedia, vol. 36, 548-555, DOI: 10.1016/j.trpro.2018.12.154

5. Novikov, A., Novikov, I., Shevtsova, A. (2019) Modeling of traffic-light signalization depending on the quality of traffic flow in the city. Journal of Applied Engineering Science, 17 (2), 175-181, DOI 10.5937/ jaes17-18117

6. GOST 33078-2014 (2016) General use automobile roads. Methods of measuring friction of vehicle wheel with the road surface. Moscow: Standardinform.

7. Shamraev, L., Borodin, K. (2015) New device EGMD2 for measuring the coefficient of adhesion according to GOST 33078-2014. Dorozhniki, 5 (5), 52-57

8. Ivanov, R., Rusev, R., Ilchev, P. (2006) Laboratory investigation of tyre sliding coefficient of friction. Transport, 21 (3), 172-181, DOI 10.3846/16484142.2006.9638062

9. Veyukov, E., Fedorov, I. (2015) Development of a laboratory installation for studying the coefficient of adhesion of a car wheel with a road surface. Proceedings of the Volga state technological University. Series: Technological, Vol. 3, 177-180. 
10. Kovalchuk, V. (1972) Operation and repair of automobile tires. Moscow: Transport publishing house.

11. Warner, C., Smith, G., James, M., Tabelle G. (1975) A.1: SAE 830612: Germane: Friction Applications in Accident Reconstructions. Reference: Traffic Accident Investigation Manual, Northwestern University, Evanston, I.U.

12. Choi, S., Bang, J., Cho, M., Lee, Y. (2002) Slidingmode control for anti-lock brake system of passenger vehicles featuring electrorheological valves. Automobile Engineering, vol. 216 (11), 897-900, DOI $10.1243 / 095440702321031441$

13. Kurakina, E., Evtukov, S. (2020) Impact of static and dynamic loads of vehicles on pavement. E3S Web of Conferences, vol. 164, 03025, DOI: 10.1051/e3sconf/202016403025

14. Glagolev, S., Shevtsova, A., Shekhovtsova, S. (2018) Basis for application of new-generation anti-icing materials as an efficient way to reduce the accident rate on roads in winter. Transportation $\mathrm{Re}$ search Procedia, vol. 36, 193-198, DOI: 10.1016/j. trpro.2018.12.063

15. Samodurova, T., Fedorova, J., Gladysheva, O. (2010) Modeling pollution on a roadside strip during winter period International. Journal of Pavement Research and Technology, vol. 3 (2), 65-71.

16. Samodurova, T. (2003) Meteorological support of winter maintenance of highways. Moscow: TIMR.

17. Teltaev, B., Kaganovich, E., Izmailova, T. (2008) Accounting for climatic operating conditions when choosing bitumen for asphalt concrete mixes. Science and technology in the road industry, vol. 2, 1720.

18. Teltaev, B., Suppes, E. (2018) Temperature in pavement and subgrade and its effect on moisture. Case Studies in Thermal Engineering, vol. 13, 100363, DOI: 10.1016/j.csite.2018.11.014

19. Belyakov, V., Molev, Yu., Vakhidov U. (2007) Influence of traffic intensity on the temperature regime of the automobile road. Bulletin of the Bauman Moscow state technical University. Ser. Engineering, vol. 3, 79-90.
20. Botvineva, N., Burlakova, I., Streltsova, T., Nesterchuk A. (2013) Investigation of the influence of weather conditions on the value of the coefficient of adhesion of tires with road surface. Fundamental research, vol. 11 (3), 407-411

21. Building rules SP 131.13330.2012 Building climatology (Building climatology)

22. Kovalev, Ya. (1966) Road and climate zoning of the territory of the USSR for the construction of asphalt concrete coatings. Application of local materials in road construction of the BSSR: collection of articles. Moscow: Transport, 64-71

23. Goretsky, L.I. (1965) Theory and calculation of cement-concrete coatings on temperature effects. Moscow: Transport, 284.

24. Superpave Performance Graded Asphalt Binder Specification and Testing (1997) Asphalt Institute Superpave (SP-1), 67.

25. Kiryukhin, G.N. (2014) For operation temperatures of the asphalt concrete pavements of highways. Roads and bridges, vol. 30, 309-328.

26. Novikov, A., Glagolev, S., Novikov, I., Shevtsova, A. (2019) Information technologies and management of transport systems development of the approach to assessing adaptation of the intersection transport model. IOP Conference Series Materials Science and Engineering, vol. 632, 012052, DOI: 10.1088/1757-899X/632/1/012052

27. Dorokhin, S., Novikov, A., Zelikov, V., Strukov, Y., Novikov, I. Shevtsova, A., Likhachev, D. (2018) Investigation of methods for calculating duration of light signal regulation cycle. Journal of Physics Conference Series vol. 1015(3), 032128, DOI: 10.1088/1742$6596 / 1015 / 3 / 032128$ 